\title{
Rare simultaneous occurrence of a ganglioglioma and diffuse astrocytoma with distinct molecular features in a teenager with neurofibromatosis type 1
}

\author{
Yongya Kim, ${ }^{1}$ Denise Malicki, ${ }^{2}$ Michael Levy, ${ }^{3}$ John Ross Crawford ${ }^{4}$
}

'Department of Neurosciences, University of California San Diego, La Jolla, California, USA 2Pathology, Rady Children's Hospital University of California San Diego, San Diego,

California, USA

${ }^{3}$ Neurosurgery, University of California San Diego, San Diego, California, USA

${ }^{4}$ Neurosciences and Pediatrics, University of California San Diego, La Jolla, California, USA

Correspondence to Dr John Ross Crawford; jrcrawford@ucsd.edu

Accepted 25 January 2022

Check for updates

(c) BMJ Publishing Group Limited 2022. No commercial re-use. See rights and permissions. Published by BMJ.

To cite: Kim Y, Malicki D, Levy M, et al. BMJ Case Rep 2022:15:e248372. doi:10.1136/bcr-2021248372

\section{DESCRIPTION}

A teenage boy with a history of neurofibromatosis type 1 (NF1) diagnosed in the first year of life presented with focal onset seizures. Neurological examination was normal. MRI of the brain revealed a fluid-attenuated inversion recovery (FLAIR) hyperintense lesion in the left inferior orbital gyrus (figure 1A) and a very subtle hyperintense FLAIR lesion in the left posterior insula (figure 1B), which were monitored by serial neuroimaging. The differential diagnosis at that time included focal areas of signal hyperintensity associated with NF1 versus a low-grade glioma. Four years later MRI demonstrated an enlargement of both lesions in association with recently diagnosed intractable epilepsy

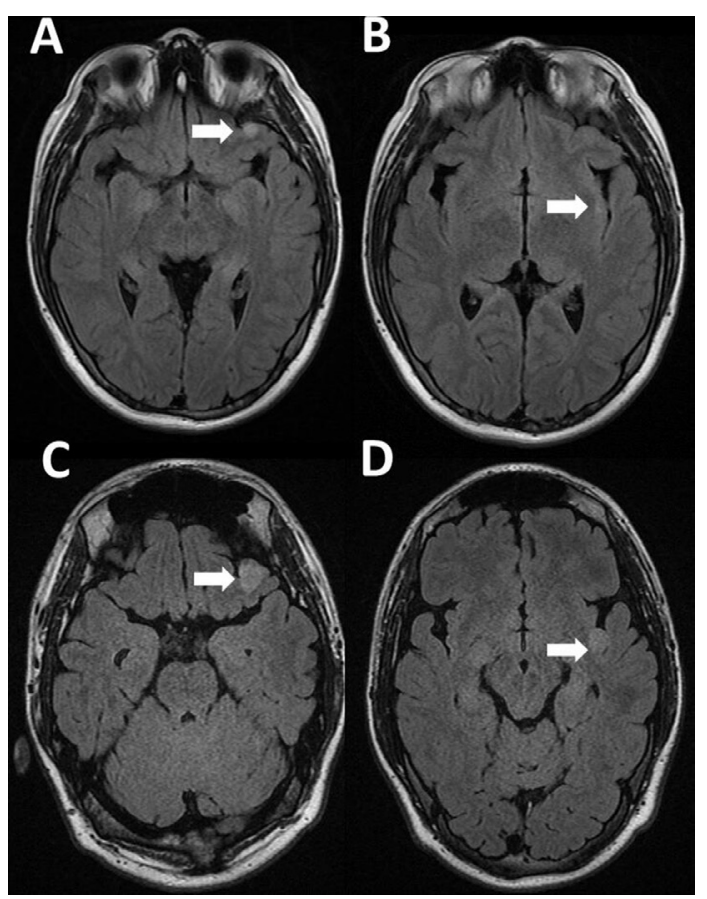

Figure 1 Neuroimaging findings of two distinct tumours in a patient with NF1. MRI of the brain revealed a fluid-attenuated inversion recovery (FLAIR) hyperintense lesion in the left inferior orbital gyrus (A) (arrow) and a very subtle hyperintense FLAIR lesion in the left posterior insula (B) (arrow), which were subsequently monitored by serial neuroimaging. Four years later, MRI demonstrated an enlargement of both the orbital gyrus (C) and insular (D) lesion in association with recently diagnosed intractable epilepsy. Only the orbital gyrus lesion showed contrast enhancement at diagnosis and progression (not shown). NF1, neurofibromatosis type 1. (figure 1C-D). Only the frontal lesion showed partial contrast enhancement at presentation and progression (not shown). The patient underwent epilepsy surgery of the dual lesions following a seizure localisation confirmatory testing that included a preoperative videoelectroencephalography and intraoperative electrophysiological monitoring. Neuropathology of the frontal lobe lesion (figure 2A) demonstrated a moderately cellular proliferation of mixed dysplastic neuronal/ganglionic and astrocytic glial cells, with eosinophilic granular bodies and focal lymphocytic infiltrates. Immunohistochemistry demonstrated diffusively positive glial fibrillar acidic protein (GFAP) staining and negative CD34 staining. Antigen KI-67 (Ki-67) had a focal positivity of $5 \%$ consistent with a diagnosis of a ganglioglioma with histologic features of a higher-grade tumour. Neuropathology of the

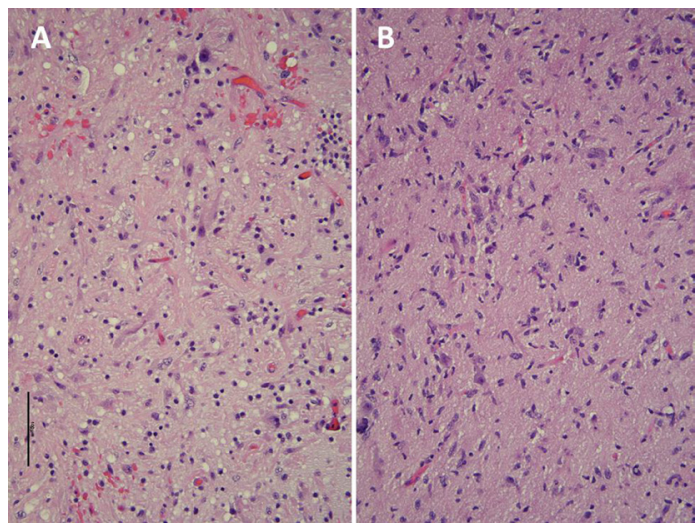

Figure 2 Neuropathological features of a ganglioglioma and diffuse astrocytoma in the same patient with NF1. Neuropathology of the frontal lobe lesion demonstrated a moderately cellular proliferation of mixed dysplastic neuronal/ganglionic and astrocytic glial cells, with eosinophilic granular bodies and focal lymphocytic infiltrates (A) Immunohistochemistry demonstrated diffusively positive glial fibrillar acidic protein (GFAP) staining (not shown) and negative CD34 staining (not shown). Antigen KI-67 (Ki-67) had a focal positivity of $5 \%$ (not shown) consistent with a diagnosis of a ganglioglioma with histological features of a higher-grade tumour. Neuropathology of the nonenhancing insular lesion. (B) Revealed a moderately cellular proliferation of elongated glial cells infiltrating around mildly atypical neurons, diffusively positive GFAP staining (not shown) and a Ki-67 focal positivity of $1 \%$ (not shown), consistent with a diagnosis of a diffuse astrocytoma. NF1, neurofibromatosis type 1 . 
non-enhancing insular lesion (figure 2B) revealed a moderately cellular proliferation of elongated glial cells infiltrating around mildly atypical neurons, diffusively positive GFAP staining and a Ki-67 focal positivity of $1 \%$, consistent with a diagnosis of a diffuse astrocytoma. In both tumours, next-generation sequencing was significant for inactivating germline mutations of NF1 and ATM, as well as variants of unknown significance (VUS) in TPR, PIK3R1, PDGFRB and RUNX1. However, the frontal lobe ganglioglioma showed a pathogenic mutation in SMAD4 and a VUS in ATP2B3 while the insular diffuse astrocytoma revealed a VUS in FGFR. Additionally, microarray analysis revealed markedly different chromosomal alterations with hypodiploidy in only the frontal ganglioglioma, suggesting an association with higher-risk disease. More than 3 years following epilepsy surgery, the patient was observed with no progression of either tumour and well-controlled seizures on monotherapy.

NF1 is an autosomal dominant condition occurring in approximately 1 in 2500-3000 individuals worldwide. ${ }^{1}$ It is associated with a loss-of-function mutation in the NF1 tumour suppressor gene $(17 . \mathrm{q} 11.2,283 \mathrm{~kb})$ that encodes a $R A S-G A S$ protein, neurofibromin, involved in the regulation of cell growth and survival. $^{23}$ Non-neurofibroma tumours associated with NF1 have been observed in $7.2 \%$ of patients ${ }^{4}$ and development of

\section{Learning points}

- Neurofibromatosis type 1 (NF1) is an autosomal dominant condition associated with a significant predisposition to develop central nervous system low-grade glioma that may be associated with epilepsy.

- The occurrence of multiple central nervous system tumours in association with NF1 have rarely been reported.

- We report the first case of a simultaneous ganglioglioma and diffuse astrocytoma with NF1 and ATM mutations, adding to the complexity of tumours associated with NF1. concomitant optic pathway and brainstem gliomas have been reported in up to $40 \%$ of NF1 patients. $^{5}$ While other multiple central nervous system tumours have been rarely reported in $N F 1,{ }^{67}$ there are no known reports of genetically distinct glial tumours found simultaneously in patients with NF1. The unique histological and molecular features of the frontal ganglioglioma and insular diffuse astrocytoma in our patient adds to the complexity of tumours associated with NF1.

Contributors YK was responsible for the design and writing of the case report. DM was responsive for the design and writing of the case report. ML was responsive for the design and writing of the case report. JRC was responsive for the design and writing of the case report.

Funding The authors have not declared a specific grant for this research from any funding agency in the public, commercial or not-for-profit sectors.

Competing interests None declared.

Patient consent for publication Consent obtained directly from patient(s).

Provenance and peer review Not commissioned; externally peer reviewed.

Case reports provide a valuable learning resource for the scientific community and can indicate areas of interest for future research. They should not be used in isolation to guide treatment choices or public health policy.

\section{REFERENCES}

1 Williams VC, Lucas J, Babcock MA, et al. Neurofibromatosis type 1 revisited. Pediatrics 2009;123:124-33.

2 Yu Y, Choi K, Wu J, et al. NF1 patient missense variants predict a role for ATM in modifying neurofibroma initiation. Acta Neuropathol 2020;139:157-74.

3 Cassina M, Frizziero L, Opocher $E$, et al. Optic pathway glioma in type 1 neurofibromatosis: review of its pathogenesis, diagnostic assessment, and treatment recommendations. Cancers 2019;11:1790.

4 Landry JP, Schertz KL, Chiang Y-J, et al. Comparison of cancer prevalence in patients with neurofibromatosis type 1 at an academic cancer center vs in the general population from 1985 to 2020. JAMA Netw Open 2021;4:e210945.

5 Bilaniuk LT, Molloy PT, Zimmerman RA, et al. Neurofibromatosis type 1: brain stem tumours. Neuroradiology 1997;39:642-53.

6 Dunn IF, Agarwalla PK, Papanastassiou AM, et al. Multiple pilocytic astrocytomas of the cerebellum in a 17-year-old patient with neurofibromatosis type I. Childs Nerv Syst 2007:23:1191-4.

7 Sakaida H, Hanakita J, Suwa H, et al. [Two cases of von Recklinghausen's disease with multiple brain and spinal tumors]. No Shinkei Geka 1992;20:51-6.

Copyright 2022 BMJ Publishing Group. All rights reserved. For permission to reuse any of this content visit

https://www.bmj.com/company/products-services/rights-and-licensing/permissions/

BMJ Case Report Fellows may re-use this article for personal use and teaching without any further permission.

Become a Fellow of BMJ Case Reports today and you can:

- Submit as many cases as you like

- Enjoy fast sympathetic peer review and rapid publication of accepted articles

- Access all the published articles

- Re-use any of the published material for personal use and teaching without further permission

Customer Service

If you have any further queries about your subscription, please contact our customer services team on +44 (0) 2071111105 or via email at support@bmj.com.

Visit casereports.bmj.com for more articles like this and to become a Fellow 